\title{
Aftershocks and On-Site Inspections Under a Test Ban: A Progress Report
}

\author{
Albert T. Smith \\ Craig Schultz \\ J.J. Zucca
}

19017100

03

September 1995

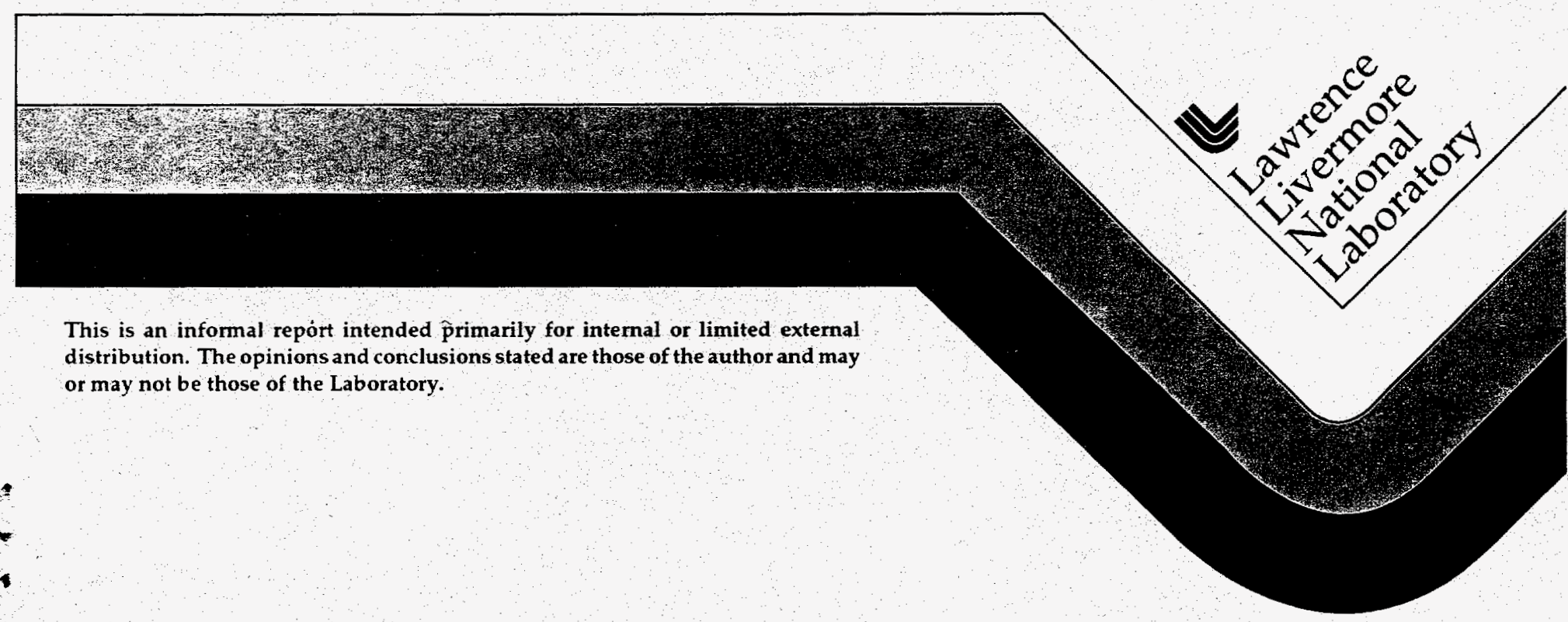




\section{DISCLAMMER}

This document was prepared as an account of work sponsored by an agency of the United States Government. Neither the United States Government nor the University of California nor any of their employees, makes any warranty, express or implied, or assumes any legal liability or responsibility for the accuracy, completeness, or usefulness of any information, apparatus, product, or process disclosed, or represents that its use would not infringe privately owned rights. Reference herein to any specific commercial product, process, or service by trade name, trademark, manufacturer, or otherwise, does not necessarily constitute or imply its endorsement, recommendation, or favoring by the United States Government or the University of California. The views and opinions of authors expressed herein do not necessarily state or reflect those of the United States Government or the University of California, and shall not be used for advertising or product endorsement purposes.

This report has been reproduced directly from the best available copy.

Available to DOE and DOE contractors from the Office of Scientific and Technical Information P.O. Box 62, Oak Ridge, TN 37831

Prices available from (615) 576-8401, FTS 626-8401

Available to the public from the National Technical Information Service

U.S. Department of Commerce

5285 Port Royal Rd.,

Springfield, VA 22161 


\section{DISCLAIMIXR}

Portions of this document may be illegible in electronic image products. Images are produced from the best available original document. 


\section{Summary}

An ambiguous seismic event detected remotely under a comprehensive test ban (CTB) may require an on-site inspection to determine the nature of the event. Provided they are present, aftershocks and microseismic events could play a key role in narrowing the inspection area and focusing the efforts of the inspectors. Of particular interest are the low-frequency, emergent aftershocks that have been observed after underground nuclear explosions at the Nevada Test Site. If these events can be shown to have unique characteristics, their detection could greatly increase the chances for a successful inspection. We have been characterizing aftershock swarms from underground explosive events and from other events that may be encountered during an inspection. This report summarizes an analysis of aftershocks following an underground explosion and microseismic events associated with routine operations at the block-caving Henderson Mine in Colorado. We used as our example of a smaller, single-point explosion the Non-Proliferation Experiment (NPE), a one-kiloton, chemical, overburied, single-point explosion whose aftershock sequence is similar to an underground nuclear explosion. We were interested in studying the Henderson mine because the caving operation is an apparent analog to the chimney formation following an nuclear event and could give rise to similar microseismic events. Mine operations at Henderson result in both low-frequency emergent events and high-frequency impulsive events. The impulsive events are primarily associated with mining explosions and a limited number are apparently from mining induced fracturing of the orebody and surrounding rock. The emergent events (hundreds per day) are apparently associated with rockfalls into the crater produced by the caving operations and have many similar characteristics to the low-frequency events from the NPE; however, the low-frequency NPE aftershocks are relatively much more impulsive than those of the Henderson Mine. Unlike the NPE or nuclear events, location of Henderson low-frequency events is extremely difficult using arrival-time methods because of their very gradual onset. Our future work will focus on array techniques for locating low-frequency events, discrimination of microseismic mining events from aftershocks of underground explosions, and the development of techniques for locating the low-frequency events. 


\section{Introduction}

Current negotiations in Geneva under the auspices of the Conference on Disarmament could lead to a comprehensive test ban treaty with provisions for on-site inspections (OSI) of ambiguous events. An OSI requires refining the reported location of an ambiguous event to a sufficiently small area to allow application of methods to resolve the nature of the event. The collapse process associated with a cavity created by an underground nuclear explosion or a large chemical explosion is a source of small aftershocks. They occur prior to both the formation of a surface crater and afterward, however aftershocks are still generated even if a surface crater does not form. Aftershocks can be detected for weeks following the explosion although the rate of occurrence falls off with time. The observation of a zone of aftershocks during an OSI could provide a basis for narrowing the inspection region and focusing the inspector's efforts.

Most of the aftershock sequences following underground explosions at the Nevada Test Site have consisted of low-frequency, emergent events compared to the aftershocks that would be expected after an earthquake of equivalent magnitude (Ryall and Savage, 1969; Smith and Geil, 1982; Jarpe et al., 1994). These events are apparently caused by the collapse of the explosion generated cavity and the caving of the rock above the cavity to form a rubble zone. If these low-frequency aftershocks are diagnostic of the explosion collapse processes, then their detection and identification during an inspection could not only narrow the inspection region but could provide a diagnostic capability to indicate that a large single-point explosion took place at a site.

To study the mechanisms generating these low-frequency seismic events in different environments and to evaluate their utility as a tool for OSI, we conducted two deployments: the first, the Non-Proliferation Experiment (NPE), evaluates the aftershocks associated with a kiloton underground chemical explosion and has similar aftershocks to a small underground nuclear explosion; and the second, the Henderson Mine, observes seismic events associated with mining. The experiments provide an opportunity to deploy a seismic network in a challenging environment for an OSI, to evaluate realistic problems which may be encountered in a mining district, and to compare source mechanisms generating the various types of seismic events. 


\section{Aftershocks from an Underground Explosion}

Experience from the Nevada Test Site includes observations of aftershocks from large underground nuclear explosions in Yucca Valley and Pahute Mesa, and from smaller nuclear detonations under Rainier Mesa (e.g., Smith and Geil, 1982; Jarpe, et al., 1994). Our concern for OSIs are aftershocks associated with smaller underground nuclear events; thus, we use aftershocks of the NPE as a case study. The NPE was a fully-contained, onekiloton, chemical explosion conducted at the Nevada Test Site (NTS) Ntunnel in Rainier Mesa that was detonated on September 22, 1993 (Denny and Zucca, 1993). We deployed a set of 15 three-component seismic stations around the NPE epicenter to delineate post-event aftershocks (Figure 1). The comparison of NPE aftershocks to earthquake and other NTS explosion aftershock sequences is reported elsewhere (Jarpe et al., 1994) and was found to be similar to other aftershock sequences from NTS explosions.

Figure 1:

Location map of seismograph stations deployed by LLNL for recording aftershocks from the NPE. The station $G Z$ is located above ground zero of the explosion. Contour intervals are given in feet. Heavy lines are dirt roads.

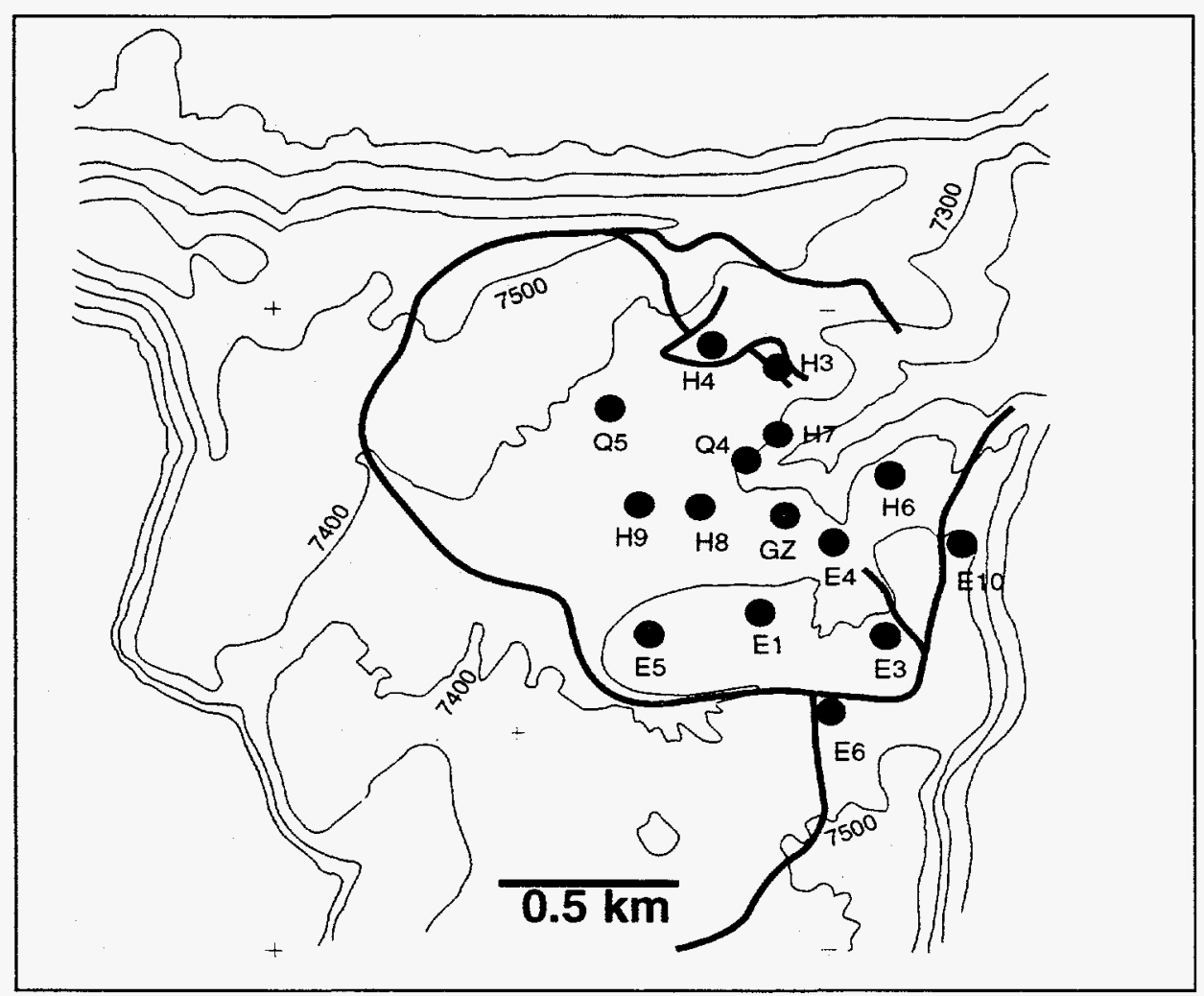




\section{Low-Frequency Events}

As mentioned in the introduction, the frequency content of the aftershocks is a potential discriminant for large underground single-point explosions. Most of the aftershocks from NTS explosions tend to have peak frequencies near $3 \mathrm{~Hz}$ (Ryall and Savage, 1969; Smith and Geil, 1982; Jarpe et al., 1994). This is in contrast to aftershocks from earthquakes of equivalent magnitude which have peak frequencies in the 50 to $100 \mathrm{~Hz}$ range (Smith and Geil, 1982).

Classifying the NPE aftershocks into both a high frequency and low frequency category, we find that low-frequency events completely dominate the seismicity (e.g., Smith and Geil, 1982; Jarpe et al., 1994). The few high-frequency events that were detected appear to originate from outside

Figure 2:

Average spectrum for NPE low- frequency event averaged over 12 events for one station. The arrows show the 2-sigma range of the peak value of the spectrum.

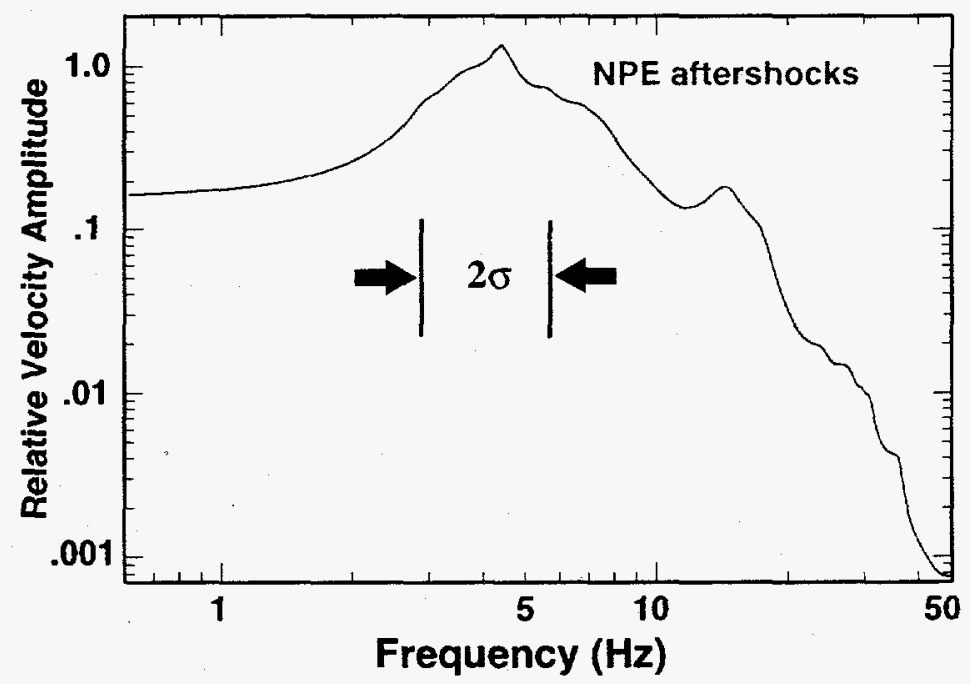

the network. Figure 2 shows an average spectrum at one seismograph station of recordings from the twelve largest low-frequency aftershocks. On average the peak frequency in velocity appears consistent in the 4-6 Hz range at all stations, which is similar with other low-frequency events from other NTS explosions. The small variation in the peak frequency between events implies that the source mechanisms are comparable and that frequency content can be used to distinguish them from earthquake aftershocks.

Although path effects such as attenuation can produce low-frequency arrivals, there is strong evidence against this in the data from the Calibration explosion. The Calibration explosion was a $300 \mathrm{lb}$ blast that was detonated in the center of the cavity for the NPE before it was mined. Its seismograms contain significant high frequency energy with peak frequen- 
Figure 3:

Comparison of the NPE calibration explosion seismogram with a synthetic and lowfrequency aftershock seismograms for one seismic station. The calculation used the known Rainier Mesa structure and an explosion source and duplicates most of the features in the data. When compared to the aftershock it is clear that its source is much more complicated.

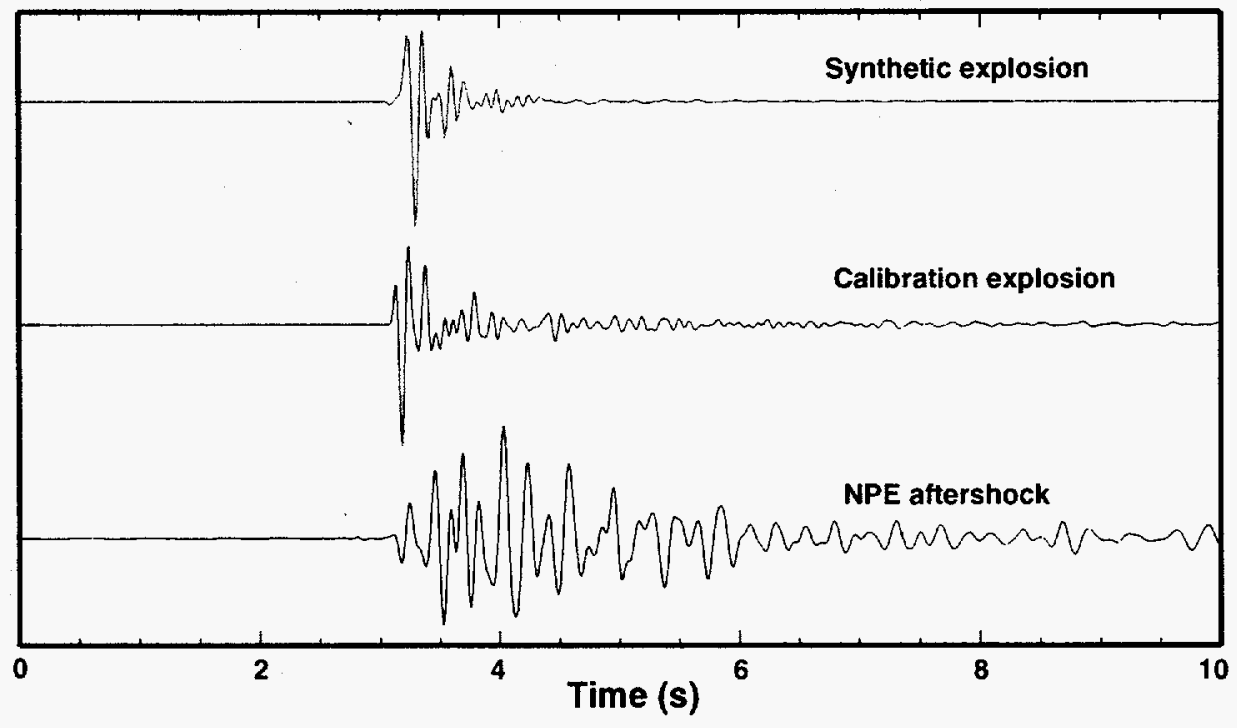

cies near $50 \mathrm{~Hz}$. The Calibration explosion data also suggest that the source mechanism for the low-frequency events is quite complicated. Figure 3 show a comparison of seismograms from a low frequency event, the Calibration explosion, and a synthetic seismogram. The synthetic seismogram was computed using a simple point-source blast and the known seismic structure from Rainier Mesa. The synthetic seismogram captures most of the features of the seismogram from the Calibration explosion and is clearly less complicated with a shorter time duration than the seismogram from the low-frequency event. We think that a plausible source for the low-frequency events is blocks of rubble within the chimney slipping and readjusting position under gravity.

\section{Location of Events}

Utilizing the network shown in Figure 1, we located the largest low frequency aftershocks which we recorded following the NPE. Locations were obtained with the code, LOCATE, developed by the U.S. Bureau of Mines in Denver, Colorado. This code was designed specifically to locate events using seismic stations distributed in a volume around the source or in areas of severe topographic relief such as may be encountered during an OSI. The code allows for a layered velocity structure, including low velocity zones.

Using a homogeneous velocity model representing the average velocity structure of Rainier Mesa, we located the calibration shot and twelve lowfrequency aftershocks. Figure 4 shows the location of these events together with circles corresponding to the largest axis of the error ellipse. The large error, 100 meters, associated with the calibration shot is a result of poor station coverage for that event. The epicentral locations of the largest 
aftershocks cluster within about 50 to 75 meters of the NPE and their error circles overlap the location of the NPE. This is consistent with aftershocks originating in the region of the chimney, but unlike a typical earthquake sequence.

Figure 4:

Map of aftershock locations. Dark dots are the computed location, the lighter circles denote the maximum error given at a $95 \%$ confidence interval. The computed location for the calibration shot is shown by the octagon. All except one error circle passes over the true location of the NPE explosion, given as box marked GZ. Not all seismic stations were operating for the calibration explosion which introduced a larger error circle.

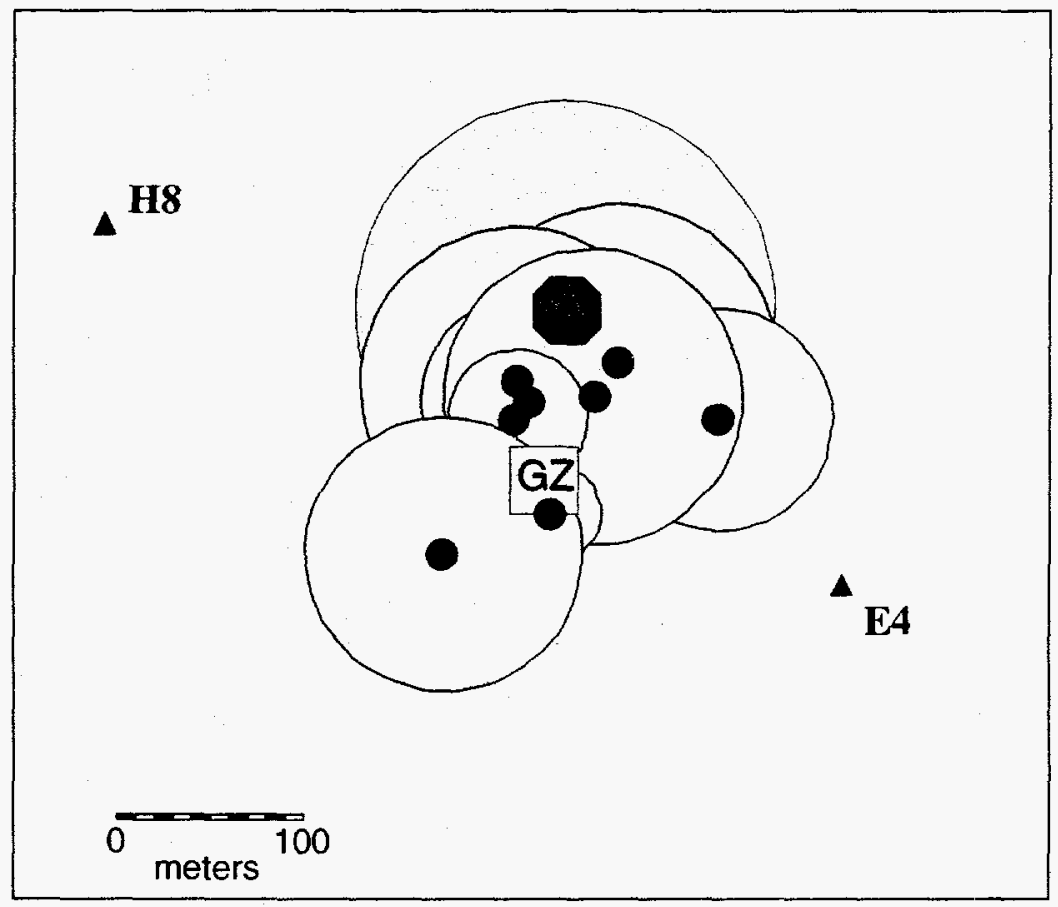

Unfortunately, the uncertainty in depth is much greater than the uncertainty in the epicentral locations. The emergent nature of these low frequency events makes it difficult to accurately pick the initial $\mathrm{P}$ arrival. With all the seismic stations on the surface, these errors translate into very little constraint on the depth. The difference between $P$ and $S$ wave travel times could provide the necessary constraint; however, the low frequency nature of the aftershocks coupled with the short travel path to the stations made picking these arrivals impossible. Thus, these locations are not accurate enough to determine if the aftershock mechanisms are related to movements in the cavity itself, shifting of the rubble zone above the actual cavity, or stress releases from regions adjacent to the cavity and chimney zone. 


\section{Henderson Mine Deployment}

Some mines, including the Henderson mine and roughly 40 to 50 more worldwide, use block caving to extract the ore. In this process the orebody is undermined and a cavity is created under the orebody. An explosive charge is placed in the roof of the cavity and a cave-in is initiated. The caving process fragments the ore in-situ and does the job that ripple-firing performs in surface mines. The caving process is not unlike the chimney formation that occurs after underground explosions, including explosions in the one kiloton range. In this case the roof of the cavity formed from the explosion falls in to create a rubble zone that extends toward the surface and may intersect the surface to form a surface crater. If low-frequency events are also associated with block caving mining operations, there would be a potential for inspectors during an OSI to confuse this seismicity with aftershocks of single-point explosions such as the NPE or a nuclear event.

We conducted a seismic deployment at the Henderson Mine in Colorado, one of two underground mines in the US employing a caving operation to extract ore, to see if we could detect and, if present, characterize lowfrequency events. Figure 5 outlines the operation of the mine. After caving the ore, the mine uses gravity to move the ore to a haulage level for extraction from the mine. Caving is initiated using one-ton shots at an average rate of one per day.

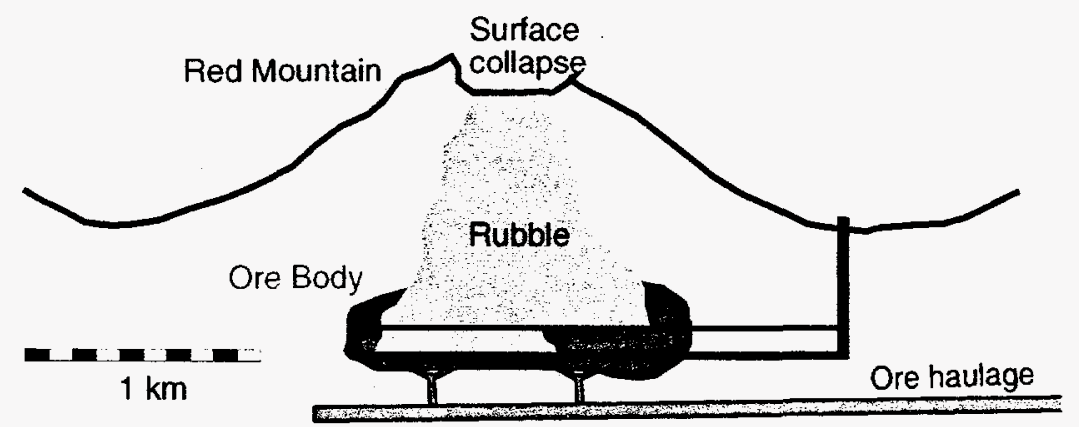

Figure 5:

Schematic of operations at the Henderson Mine, Colorado. The ore body, shaded darkly, lies 1.5 kilometers directly under the peak of Red Mountain. At successively deeper depths a mesh of tunnels are laid out through the ore body and the roof of interconnecting tunnels are blow to initiate gravitational fracturing and collapse of the overlying ore. As the ore is extracted the collapse continues until a subsidence crater forms at the surface, in this case, near the peak of Red Mountain. Extraction of ore continues until waste is encountered, then mining is initiated at the next deeper level. As the ore is extracted, it is dumped down chutes for loading on a train and hauled $15 \mathrm{~km}$ through the Continental Divide to the next valley for processing. 
We deployed thirteen seismic stations around the Henderson mine. Nine of these stations transmitted data by digital radio telemetry to a central site. The rest of the stations recorded the data locally on site. Figure 6 is a location map showing the stations relative to the zone of mining and the topography. To constrain the depths of events within the rubble zone, we placed seismic stations near the top of the mountain and along its side, which required backpacking equipment up the mountain to elevations greater than 11,500 feet. During winter months, up to 20 feet of snow could be present on the mountain and within the valleys. The remaining stations were located on bedrock adjacent to roads within the valleys or passes.

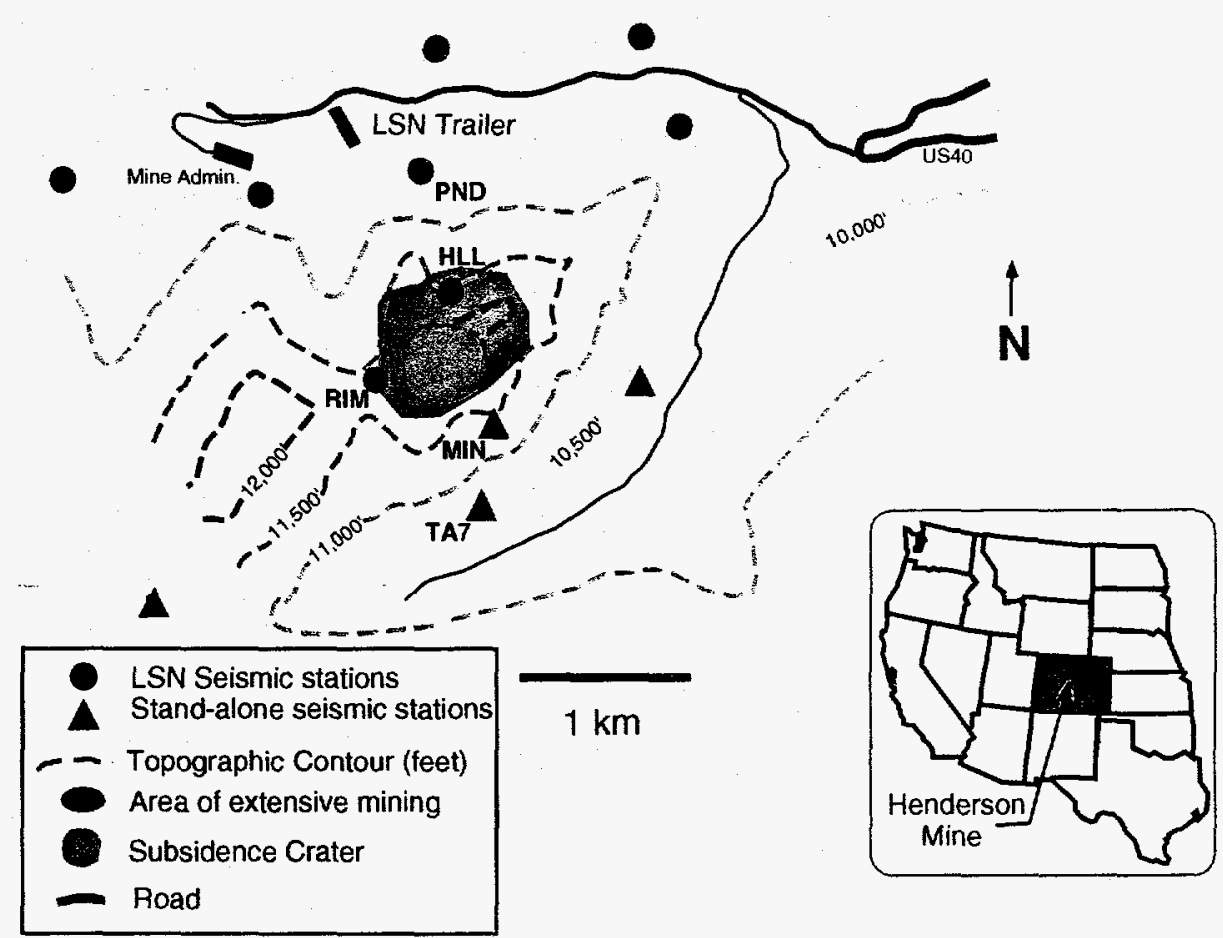

Figure 6:

Map view of Red Mountain and the Henderson Mine workings, together with seismic station locations. The shaded area indicates the plan view of the mine workings, 1.5 kilometers below the peak, where ore extraction takes place. The subsidence crater roughly occupies the smaller, darker shaded region near the peak. Five key seismic stations are identified on the map: RIM and HLL are near the top of the mountain, adjacent to the subsidence crater; PND is on the north flank of the mountain; MIN is halfway up the mountain on the south flank; and TA7 denotes the location of an $\$ 750$ seismometer sampling at $500 \mathrm{~Hz}$ for better resolution of the source.

\section{Seismicity Rates}

The seismicity rate strongly depends upon mining operations. During a normal operating day, the mine is extracting ore between 6 AM and $2 \mathrm{AM}$ local time. Between $2 \mathrm{AM}$ and $6 \mathrm{AM}$, maintenance is performed. This introduced a daily periodicity in the seismicity rate which is observed as a 
Figure 7:

Seismicity rate in events per hour plotted versus time over a one month period. High rates are observed during the day when active mining occurs; much lower rates occur during holiday and weekend shutdowns. strong peak in seismicity late in the day and a minimum early in the morning. Most mine blasts are conducted during the shift-change, typically between 3:30 and 4:00 PM local time. These are high-frequency impulsive events (peak frequencies typically $>100 \mathrm{~Hz}$ ). Normally, $2500 \mathrm{lb}$. aggregate explosions are used to collapse the roof using 15 holes detonated over a total duration of $15 \mathrm{~ms}$. Thus, they appear very impulsive at typical seismic frequencies. These explosions occur on the order of a few per week. However, $500 \mathrm{lb}$. explosions are conducted daily during the shift change for the purpose of maintenance of the caving process. For the same purpose, 100 lb. explosions are possible during a shift. Weekend shutdowns range from 3 to 4 days and are associated with a marked reduction in seismicity.

Figure 7 plots the number of detected events per hour over a one month period which includes the July 4 holiday. The rate shows a strong correlation with the mine operations, increasing during active caving and decreasing during maintenance periods or during shutdowns. Prior to a shutdown starting July 1 , the mine was in full operation, extracting ore in actively caving areas and setting explosive charges to initiate caving in new regions. High seismicity is observed during this period, roughly 10 to 20 events per hour. However, the rate decreases to a lower level of 1 to 5 events per hour during the 4th of July shutdown. Even though the mine was shutdown, seismicity still occurred at a rate comparable to that observed several weeks after a $1 \mathrm{kt}$ underground explosion (Jarpe et al., 1994).

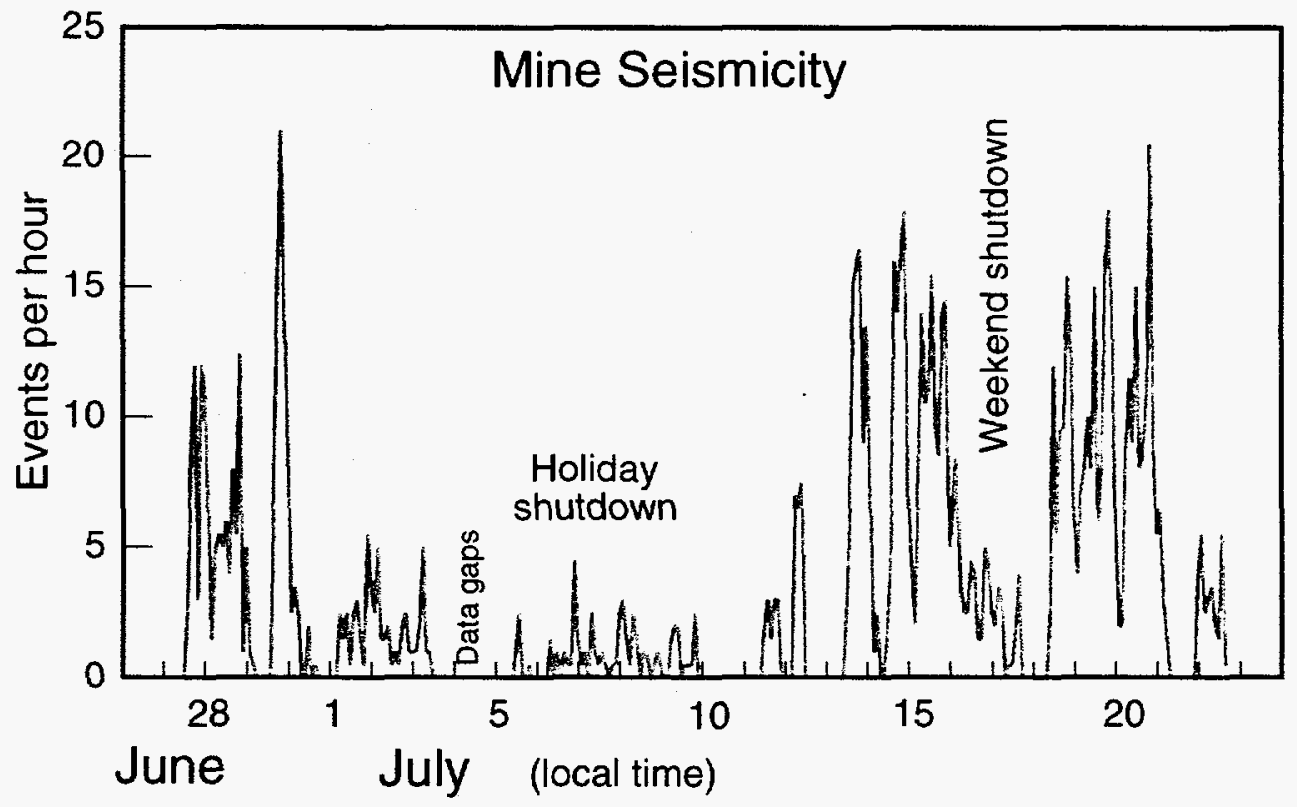




\section{Low Frequency Events}

The vast majority of events observed from the mine are low-frequency and emergent (peak frequency near $3 \mathrm{~Hz}$ ) and probably associated with the caving process. Figure 8 compares waveforms from the Henderson Mine to a waveform from an emergent, low-frequency event recorded following the NPE. Figure 9 shows several waveforms from a mining explosion. The explosion waveforms clearly contain higher frequencies. The recording of both high- and low-frequency events at the same stations indicates that the low-frequencies are not the result of path attenuation but rather must come from the source.

Although most mine events are also emergent and low-frequency in nature, they have a different character than the low-frequency events from the NPE. The mine events are much more emergent, often showing a slow increase in amplitude over several seconds rather than 1 second as for most NPE events. Figure 8 shows the initial part of the seismogram amplified by 10 times to better indicate the onset of the first arrival. The maximum amplitude of the seismogram is indicated by a horizontal bar. Note the much larger time difference between the first arrival and the maximum amplitude for the Henderson mine events.

Figure 8:

Waveforms of low-frequency events from the Henderson Mine compared to a low-frequency aftershock fro the NPE. The initial onset of the waveforms are amplified by a factor of 10 to illustrate the difficulty in picking the first arrival. The bar indicates the maximum amplitude part of the seismogram. All the events are emergent; however, the mine events show a much more gradual rise in amplitude.

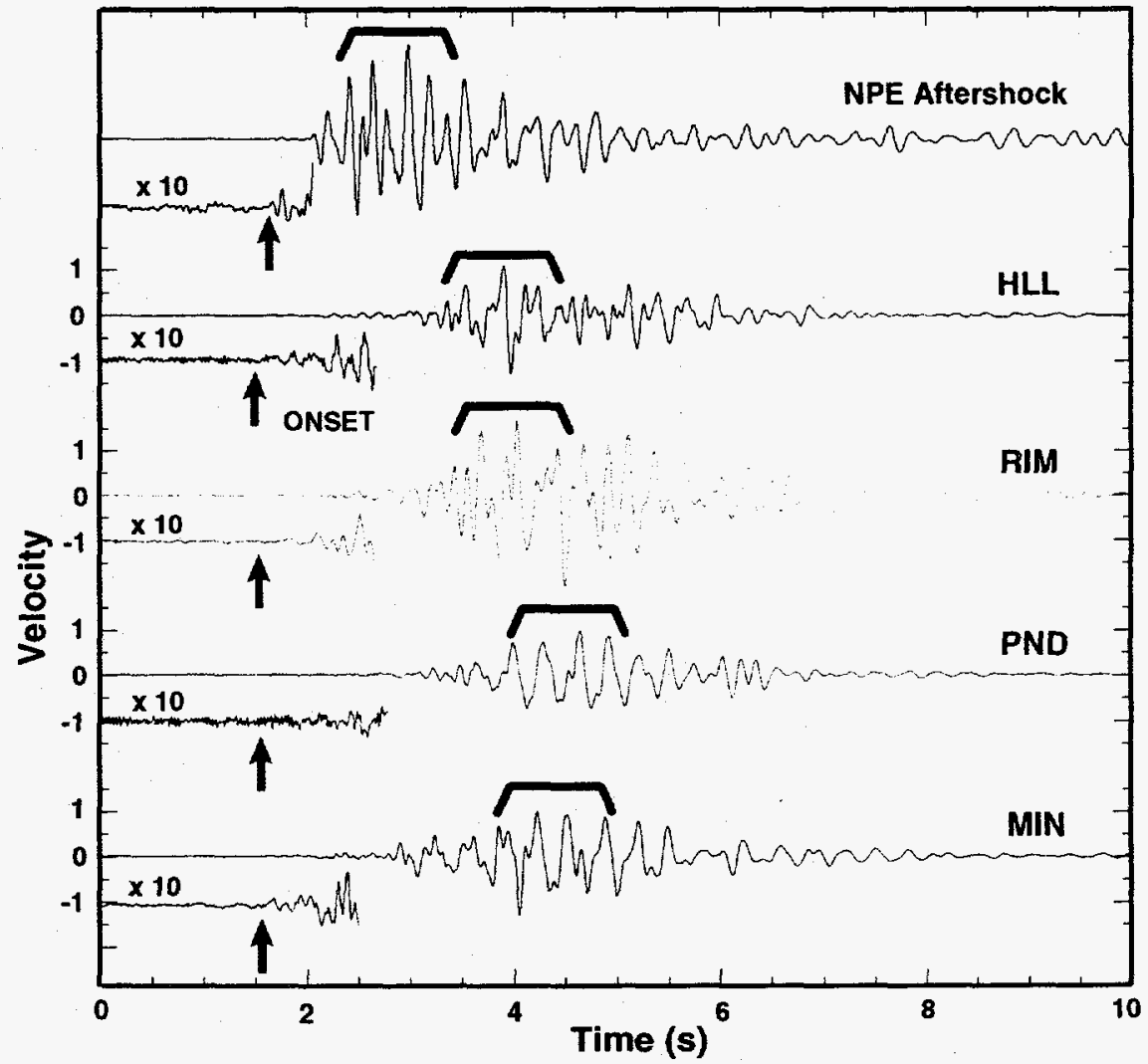


Figure 9:

Seismograms from Henderson mining explosions. The arrow indicates the impulsive onsets. Note the low frequencies at station RIM.

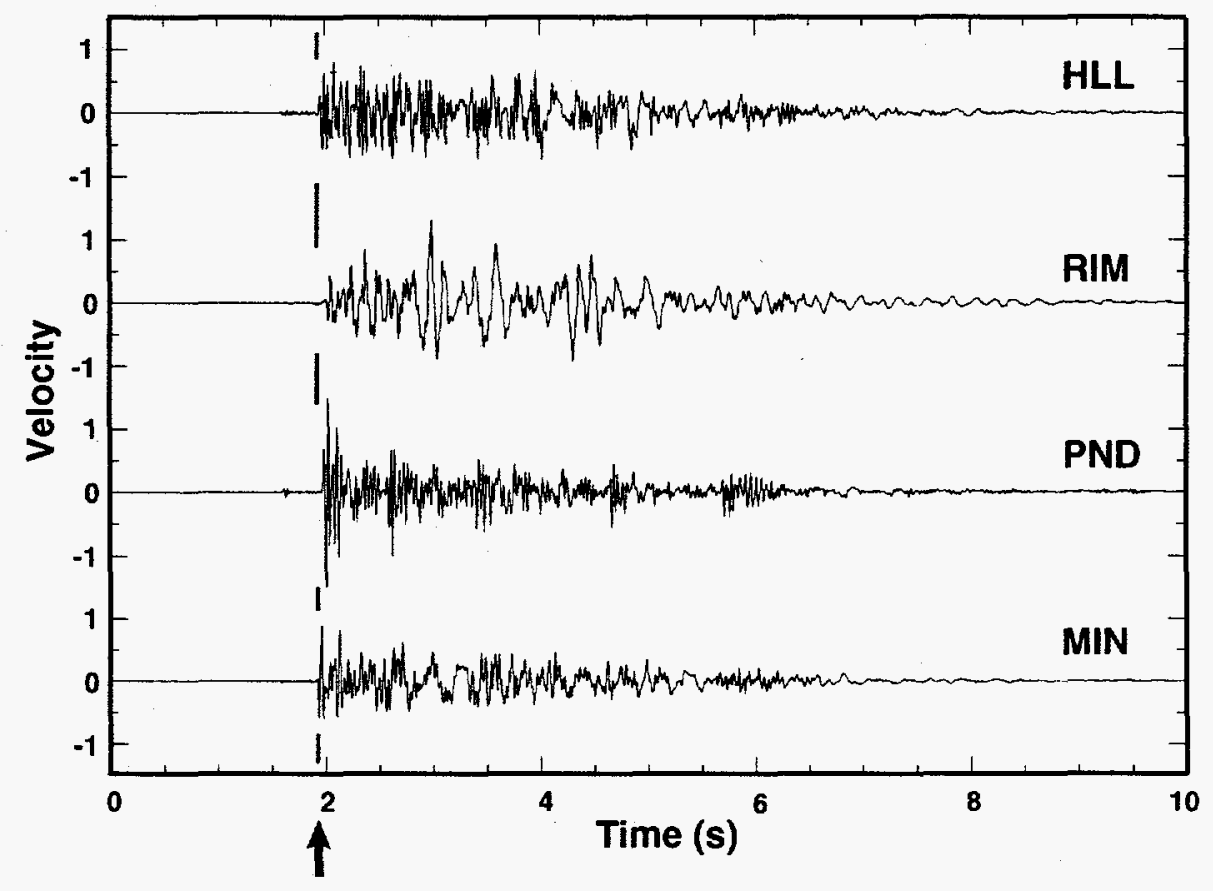

Although arrival times cannot be measured to enough accuracy to allow accurate locations, other evidence suggests that the low-frequency events originate near the subsidence crater. On figure 8, the four traces from a Henderson event show true amplitude in relation to each other. Amplitudes for stations HLL and RIM, which are located near the subsidence crater, are the largest for the emergent event. In figure 9, HLL and RIM are smaller for the explosion, consistent both with the explosion's deeper origin in the mine and with the source of emergent events nearer the subsidence crater. Rock falls from the vertical walls of the subsidence crater could explain the event location and the long build up to the maximum amplitude. Rockfalls have been shown to have very emergent onset as rocks break, slide down the almost vertical wall of the crater with multiple bounces, and impact the crater floor (Neri and Malone, 1989 ). The sound and rising dust from many such events were observed during the installation, occasional servicing, and removal of station RIM.

Not all impulsive events were observed to be explosions in the mining zone. From a sample of approximately 30 larger presumed rockfalls and explosions during one day, one impulsive event occurred which does not exhibit features of an explosion or occur during a shift change. Explosions observed on that day all show compressional first motions at the stations; however, the anomalous event exhibits dilational first motions and prominent shear waves at PND. Comparing travel times of its impulsive first arrivals to those of shots, the event's location is within 20 meters of shots during that 
day. These observations suggest that the source could be due to fracturing in the host rock as the ore breaks and descends during mining .

Smaller emergent events are harder to locate, except using relative amplitudes of the seismic stations, since the very small amplitudes of the onset are lost in the seismic noise and we are unable to compare their relative travel times. The emergent arrivals of collapse seismicity at Henderson, then, makes it impossible to use conventional picking to accurately invert for epicentral locations. Cross-correlation algorithms using the complete waveform may be able to categorize and associate events within specific regions (Harris, 1991).

\section{Location of Events}

The gradual emergent onset of the Henderson events prevents timing these onsets for precise locations using traditional location methods such as LOCATE. Figures 8 and 9 illustrate our dilemma by comparing seismograms for a shot and a low-frequency event. To obtain accurate locations, the first arrivals need to be known to within few hundredths of a second. The four traces in Figure 9 for a shot within the mining zone, approximately $1.5 \mathrm{~km}$ beneath the peak, have impulsive onsets which satisfy this criteria and provide robust locations. We used the LOCATE program to locate mining explosions. A homogeneous velocity model is adequate to place the events within a few hundred meters of the known location. It is difficult to time the low-frequency events in Figure 8 to $0.1 \mathrm{~s}$, which does not allow an accurate location to be calculated.

Although methods such as LOCATE fail to locate the emergent events, there may be nontraditional methods that will work. Array techniques may provide some measure of location capability for these events. One method is to deploy mini arrays and triangulate a location using frequencywavenumber methods. We did deploy an array at Henderson, but the array aperture was intended for high-frequency events and does not provide adequate wavenumber resolution at frequencies of 3 to $5 \mathrm{~Hz}$. Any future deployments should use arrays with larger apertures. 


\section{Conclusions and Future Work}

In this study we investigated the properties of low- and high-frequency aftershocks and microseismic events from a representative, single-point underground explosion at NTS, the Non-Proliferation Event, and an active block-caving mine, the Henderson Mine. The low-frequency aftershocks that appear to follow all underground explosions at NTS also occur at the Henderson mine. This study demonstrates their association with the mining activities. Although the peak frequencies of the low-frequency events at Henderson and NTS appear to be the same, there are characteristics that may make discrimination between the two possible: 1) the longer emergence to maximum amplitude that is observed in the Henderson events; and 2) near surface location of emergent mine events. These emergent events appear to be caused by falling boulders in the subsidence crater, but their emergent nature makes them difficult to locate. We were able to locate many of the low-frequency aftershocks following the NPE, but not similar events from the Henderson mine due to their very gradual onset. These results emphasize the potential importance, and the difficulty, of accurate locations for emergent events within a mining district. If OSIs are to be successful, it will be necessary to separate seismic activity generated by normal mining operations from aftershocks of a clandestine test.

Our future work will concentrate on developing robust location strategies for the low-frequency events and examining their occurrence in other types of mining operations. We plan to examine the triangulation capability of networks of mini-arrays for the location of the low-frequency events. This could reduce the number of sites needed for seismic instruments and improve the detection of signals within a noisy mine environment. It might also be possible to use cross-correlation techniques to calculate relative arrival times to master waveforms. Finally, the caving operations at the Henderson Mine generate an unusually large number of low-frequency events from rock falls. Although important for future verification, these mines are probably not typical of most underground mines. We also plan to examine other types of collapses, for example, those that occur during long-wall coal mining. 


\section{Acknowledgments}

This study would not have been possible without the contributions of numerous individuals during the deployments: Don Rock, Pat Lewis, and Steve Jarpe from LLNL; and Steve Becker, Michael O'Connor, and Scott Tibbits from EG\&G, Las Vegas. Francois Hueze of LLNL was instrumental in arranging the Henderson deployment, and the Henderson Mine allowed us on-site and provided generous assistance.

This work was performed under the auspices of the U.S. Department of Energy by the Lawrence Livermore National Laboratory under contract number W-7405-ENG-48, in support of the Comprehensive Test-Ban Treaty Research and Development Program sponsored by the DOE Office of Non-Proliferation and National Security. 


\section{References}

Denny, M. D., and J. J. Zucca, 1993. DOE Non-Proliferation Experiment Included Seismic Data, EOS 74, 527.

Harris, D., 1991. A waveform correlation method for identifying quarry explosions, Bull. Seism. Soc. Am. 53, 989.

Jarpe, S., P. Goldstein, and J. Zucca, 1994. Comparison of the Non-Proliferation Experiment aftershocks with other Nevada Test Site events, Proceedings, Symposium on the Non-Proliferation Experiment, DOE Conf9404100, 8-34.

Neri, G. and S. D. Malone, 1989. An analysis of the earthquake time series at Mount St. Helens, Washington, in the framework of recent volcanic activity, J. Vol. Geo. Res. 38, 257.

Ryall, A. and W. U. Savage, 1969. A comparison of seismological effects for the Nevada underground test BOXCAR with natural earthquakes in the Nevada region, J. Geophys. Res. 74, 4281.

Smith, A. T. and R. G. Geil, 1982. Microseismicity following an explosion, Earthquake Notes 53, 10. 